\title{
Neurologic complications and good outcomes from dengue virus infections
}

If there were doubts about the neurologic importance of dengue virus infection, the current paper by Dr. Pal et al., "Clinico-radiological Profile and Outcome of Dengue Patients with Central Nervous System Manifestation - A Case Series Study in the Eastern India Tertiary Care Hospital" [1] is further proof of dengue's significance in this domain. The authors present 9 cases of dengue with neurologic complications: Encephalitis, meningitis, encephalopathy, and acute disseminated encephalomyelitis; cared for over a 15 months period in 2013-2014 in an Eastern India hospital. The patients were ages $12-45$ years, with a male: female ratio of 2:1 and all were reported to have made good recoveries from their illnesses.

The paper is important in showing dengue can be a frequent or leading cause of encephalitis in endemic areas, and a primary expression of infection. In this way, dengue encephalitis will likely prove to be a marker of virus expansion into new geographic regions. Also important is that patients from adolescent to middle age adults, made good recoveries with supportive care or with steroids in one case of immune-mediated consequences. The paper contributes important information on the natural history of encephalitic dengue and has implications for the practical care and prognosis of patients. A good outcome is probably related to patients' age and that many cases were primary dengue in this series. Future studies may include more subtle aspects of neurologic testing, and can expand on outcomes by serotype, in secondary dengue, on the natural history at the extremes of age, and comorbidity factors. Hospital cases with critical care requirements also will provide worthwhile reports, to elucidate the pathophysiologic mechanisms and suggest adjunct therapies to improve the outcomes.

The authors used MAC-ELISA anti-dengue virus (anti-DENV) IgM detection in serum to diagnose dengue, and it is assumed that they detected an acute primary dengue in most cases. Acute primary dengue is $\mathrm{IgM}+$ and IgG-; acute secondary may be $\mathrm{IgM}+\mathrm{IgG}+$ or IgM- IgG+.. ${ }^{[2]}$ The most sensitive and useful tests are those that combine $\operatorname{IgM} \operatorname{IgG}$ and NS1 antigen testing.
There are limitations of anti-DENV IgM tests alone that include: Inability to identify the infecting serotype; potential cross-reactivity with other Flaviviruses or their vaccines (Japanese encephalitis, yellow fever, and tick-borne encephalitis), other conditions (hepatitis A, leptospirosis, rheumatoid factor, and rheumatologic disorders); ${ }^{[3]}$ and the persistence of $\operatorname{IgM}$ for $\geq 60$ days, ${ }^{\left[{ }^{[4]}\right.}$ a feature that calls into question its use in dengue-endemic areas as a confirmatory test for present illness. The authors did explain in their setting, this was the only available dengue diagnostic, and it is assumed that the results of IgM tests alone were interpreted in conjunction with the medical history, clinical and epidemiologic information. If not at the start of a dengue season, investigators should exclude from study patients with a history of febrile illness prior to $2-3$ months. Adoption of point-of-care testing by several methods and with serial samples could increase the precision in future reports.

The current report ${ }^{[1]}$ shows the cases of dengue encephalitis to be associated with multifocal white matter magnetic resonance imaging (MRI) abnormalities in one, diffuse brain edema in another, and bilateral thalamic, bilateral thalamic and left medial temporal, or bilateral thalamic and splenium of corpus callosum changes in 3 others. These MRI changes have previously been reported with dengue, but the dominance of thalamic abnormalities further identifies dengue encephalitis with the diencephalic or deep gray nuclei pattern characteristic of several other Flaviviruses. Similar subcortical involvement is described in encephalitis caused by Flaviviridae family members: West Nile virus, St. Louis encephalitis virus, tick-borne encephalitis virus, Murray Valley encephalitis virus, Rocio virus, and 2 Togaviridae family members: Eastern Equine and Western Equine encephalitis viruses. ${ }^{[5,6]}$ The distribution would be consistent with virus gaining access to the central nervous system (CNS) via choroid plexus, by infected vascular endothelial cells or circulating white blood cells.

Curiously, only one cerebrospinal fluid (CSF) in this series was IgM+, although CSF IgM has been suggested as a marker of neuroinvasive disease. Still, this result 
is consistent with the literature: That the sensitivity of serology can be low, and that dengue-specific IgM antibodies have been found in CSF of 22-33\% of patients with dengue encephalitis. ${ }^{[7,8]}$ Host or viral factors that render the CSF IgM positive including serotype, viral load, and the contribution of disease duration, CNS distribution or severity, are not known from the present study.

In summary, the general clinical features of dengue are well characterized, and new reports continue to expand our understanding of accompanying CNS disease. No antiviral therapy with efficacy for dengue exists, but progress in the therapy of other Flaviviruses may one-day be generalizable for dengue. This year or the next will probably bring a universal vaccine that includes all 4 serotypes of dengue. There are presently several vaccines at various clinical stages, one at an advanced development and testing stage is Sanofi's ChimeriVax, a tetravalent vaccine of 4 recombinant live attenuated viruses (yellow fever 17D/DEN chimeric viruses). ChimeriVax has finished the phase III clinical trials which have included Asia. ${ }^{[9]}$ Vaccination would have an impact on the estimated 4 billion people at risk for contracting dengue.

Marylou V. Solbrig

Department of Pharmacology and Toxicology, School of Pharmacy, University of Kansas, Lawrence, KS 66045, USA

Address for correspondence:
Dr. Marylou V. Solbrig,
Department of Pharmacology and Toxicology,
1251 Wescoe Hall Drive Rm 5040,
University of Kansas, Lawrence KS 66045 USA.
E-mail: msolbrig3@ku.edu

\section{References}

1. Pal S, Sen K, Biswas NM, Ghosal A, Jaman SR, Kumar KY. Clinico-radiological profile and outcome of dengue patients with central nervous system manifestation - A case series study in the Eastern India Tertiary Care Hospital. J Neurosci Rural Pract 2015;7:114-20.

2. Blacksell SD, Newton PN, Bell D, Kelley J, Mammen MP Jr, Vaughn DW, et al. The comparative accuracy of 8 commercial rapid immunochromatographic assays for the diagnosis of acute dengue virus infection. Clin Infect Dis 2006;42:1127-34.

3. Berlioz-Arthaud A, Gurusamy A. Comparison of PanBio dengue IgM ELISA assay with pentax dengue IgM particle agglutination assay to evaluate factors affecting false positive results. Southeast Asian J Trop Med Public Health 2008;39:55-61.

4. Hunsperger EA, Yoksan S, Buchy P, Nguyen VC, Sekaran SD, Enria DA, et al. Evaluation of commercially available anti-dengue virus immunoglobulin M tests. Emerg Infect Dis 2009;15:436-40.

5. Oyer RJ, David Beckham J, Tyler KL. West Nile and St. Louis encephalitis viruses. Handb Clin Neurol 2014;123:433-47.

6. Solbrig MV, Hasso AN, Jay CA. CNS viruses - Diagnostic approach. Neuroimaging Clin N Am 2008;18:1-18, vii.

7. Soares CN, Faria LC, Peralta JM, de Freitas MR, Puccioni-Sohler M. Dengue infection: neurological manifestations and cerebrospinal fluid (CSF) analysis. J Neurol Sci 2006;249:19-24.

8. Carod-Artal FJ, Wichmann O, Farrar J, Gascón J. Neurological complications of dengue virus infection. Lancet Neurol 2013;12:906-19.

9. Capeding, Tran NH, Hadinegoro SR, Ismail HI, Chotpitayasunondh T, Chua MN, et al. Clinical efficacy and safety of a novel tetravalent dengue vaccine in healthy children in Asia: a phase 3, randomised, observer-masked, placebo-controlled trial. Lancet 2014;384:1358-65.

This is an open access article distributed under the terms of the Creative Commons Attribution-NonCommercial-ShareAlike 3.0 License, which allows others to remix, tweak, and build upon the work non-commercially, as long as the author is credited and the new creations are licensed under the identical terms.

\begin{tabular}{|l|l|}
\hline \multicolumn{2}{|c|}{ Access this article online } \\
\hline Quick Response Code: & Website: \\
\hline & www.ruralneuropractice.com \\
\cline { 2 - 2 } & \\
\hline & \\
\hline
\end{tabular}

How to cite this article: Solbrig MV. Neurologic complications and good outcomes from dengue virus infections. J Neurosci Rural Pract 2016;7:3-4. 